\title{
Assessment of pollutant emissions and energy efficiency of four commercialized charcoal stoves with modified Chinese cooking stove protocol
}

\author{
Yixiang Zhang ${ }^{1,2,3}$, Jiong $\mathrm{Hao}^{1,2,3}$, Yuguang Zhou ${ }^{1,2,3}$, Zongxi Zhang ${ }^{1,2,3}$, \\ Li Chen ${ }^{1,2,3 *}$, Renjie Dong ${ }^{1,2,3}$ \\ (1. College of Engineering, China Agricultural University, Beijing 100083, China; 2. Key Laboratory of Clean Production and \\ Utilization of Renewable Energy, Ministry of Agriculture, Beijing 100083, China; 3. National Center for International Research of \\ BioEnergy Science and Technology, Ministry of Science and Technology, Beijing 100083, China)
}

\begin{abstract}
Charcoal stove is widely used in the developing countries especially in Africa and Central America. Even reported to have a high impact on human health, stoves promoted in the related areas still mainly focus on fuel saving and little knowledge was reported for the stove performance in the field. This research evaluated four commercialized charcoal stoves with clay baseline stove using a modified Chinese cooking stove protocol that considered the local cooking habit to make the testing results more useful for the local stove promotion. The results showed that the thermal efficiency of tested charcoal stoves ranged from $38.7 \%$ to $47.5 \%$, and the cooking power was around $640-1200 \mathrm{~W}$. The CO emission factors of the improved stove had a $60 \%$ reduction compared with baseline stove. Different indicators reporting the same aspect of the stove were evaluated, and it suggested choosing the indicators according to the project requirements.
\end{abstract}

Keywords: charcoal stove, energy efficiency, pollutant emissions, carbon dioxide emissions, testing protocol, cooking DOI: $10.25165 /$ j.ijabe.20181102.3637

Citation: Zhang Y X, Hao J, Zhou Y G, Zhang Z X, Chen L, Dong R J. Assessment of pollutant emissions and energy efficiency of four commercialized charcoal stoves with modified Chinese cooking stove protocol. Int J Agric \& Biol Eng, 2018; 11(2): 202-207.

\section{Introduction}

Energy poverty is rife both in developing countries and poor regions in developed countries ${ }^{[1,2]}$. An important domestic energy requirement is that used for cooking ${ }^{[3,4]}$. Among the energies carriers available for residential cooking such as biomass, kerosene, solid alcohol, coal, electricity or liquefied petroleum gas (LPG), biomass is usually the cheapest and easiest way to meet the basic requirements ${ }^{[5]}$. Biomass cooking energy requirements accounts for more than $70 \%$ in rural India ${ }^{[6]}$ and more than $60 \%$ in rural China $^{[7]}$. This fraction is higher in relatively less developed countries such as Ethiopia and Indonesia ${ }^{[8]}$. Multiple fuel use strategies have been carried out in some countries ${ }^{[9,10]}$, because switching everyone to modern energy carriers takes time to accomplish.

At the same time, using the less efficiency residential fuel combustion device for cooking has become one of the most significant source of air pollution which will have great influence on the human health especially for women and children as they are

Received date: $2017-09-18 \quad$ Accepted date: $2018-01-29$

Biographies: Yixiang Zhang, $\mathrm{PhD}$ candidate, major in biomass engineering, Email: yinhezhixing2005@163.com; Jiong Hao, Master candidate, major in biomass engineering, Email: 1298128998@qq.com; Yuguang Zhou, PhD, Associate Professor, major in biomass engineering, Email: zhouyg@cau.edu.cn; Zongxi Zhang, $\mathrm{PhD}$ candidate, major in emission examining of biofuel combustion, Email: jnzhangzongxi@163.com; Renjie Dong, Professor, major in biomass engineering, Email: rjdong@cau.edu.cn.

*Corresponding author: Li Chen, Associate Professor, major in biomass engineering. China Agricultural University, No.17 Qinghua East Road, Haidian District, Beijing 100083, China. Tel: +86-10-62737858, Fax: +86-1062737885, Email: chenli329@cau.edu.cn. spending more time in the house ${ }^{[11,12]}$. The adverse health impacts reported in literatures include eye symptoms, lung function and blood pressure caused by exposure to pollutants like particulate matter $2.5\left(\mathrm{PM}_{2.5}\right)$, carbon monoxide $(\mathrm{CO})$ or polycyclic aromatic hydrocarbons (PAHs) ${ }^{[8,13-16]}$.

As one of the most efficient way to solve the problem in short time, clean cooking charcoal stove promoting programs are carried out in many countries such as India and China for many years ${ }^{[17,18]}$. Some of the promotion programs have significantly improved the living standards of the people, but still not as good as expected. One reason can be more attention was paid to the thermal performance improvement but not the emission performance; another can be the programs were mainly promoted by the government policy instead of marketing.

Apart from these awareness problems, one of the most significant technical problems is the stove performs differently between laboratory test and field test ${ }^{[19,20]}$. Lots of studies have been done in the laboratory using laboratory testing methods, such as Water Boiling Test (WBT) v4.2.3 $3^{[21-24]}$. However, as the cooking habits and fuel condition changes from one to another in the field, test results with well-controlled laboratory conditions can be quite different from the field tests for the same stove ${ }^{[25-27]}$. Even in the laboratory, results of various testing sequences from different laboratory testing methods will put the same stove on various tiers $^{[28]}$. Meanwhile, many conceptual errors have been analyzed for the laboratory testing methods ${ }^{[29]}$. Developed new testing sequence, which is more representative of the stove promotion area is needed.

This study developed a modified Chinese cooking stove protocol by considering the local cooking habit to make the testing 
results more useful for the local promotion. Four developed charcoal stoves and one baseline stove were evaluated with thermal performances indicators including efficiency and the cooking power, and emission performance indicators including $\mathrm{CO}$ emission factor and $\mathrm{CO} / \mathrm{CO}_{2}$ ratio.

\section{Materials and methods}

\subsection{Fuel}

A local charcoal was used for the testing. The charcoal was pressed using pine wood sawdust into a hollow bar to ensure enough air ventilation. The fuel was broken into $4 \mathrm{~cm}$ length pieces before ignition to match the requirements of the small combustion chamber. Solid alcohol was used for ignition which rendered the starting phase convenient and reproducible. One drawback using the solid alcohol was that it generated much water at the ignition phase especially when we put the pot on, the water droplet could be seen at the bottom of the pot. All the fuel and kindling were batch loaded before ignition according to the manufacturer's instructions. The fuel analysis was listed in Table 1. The dry basis higher heating value of the fuel was $22.129 \mathrm{MJ} / \mathrm{kg}$.

Table 1 Ultimate analysis and proximate analysis of the fuel

\begin{tabular}{cccc} 
Ultimate analysis (dry basis) & Content $\%$ & Proximate analysis & Content $/ \%$ \\
\hline Carbon & 59.9 & Ash & 18.26 \\
Hydrogen & 2.81 & Volatile matter & 25.80 \\
Nitrogen & 0.38 & Fixed carbon & 50.9 \\
Sulfur & 0.22 & Moisture & 5.04 \\
\hline
\end{tabular}

\subsection{Stoves}

Table 2 is five stoves tested in this research.

1) The very cheap baseline stove was mainly made of clay with an iron handle to carry it. It was $28 \mathrm{~cm}$ diameter and $24 \mathrm{~cm}$ height, with the combustion chamber to be $18 \mathrm{~cm}$. The door at the bottom was designed to control the air went into the stove which would further change the fire power, but the stove did not have a rubber handle, so this one should use some tools to operate it during the combustion to avoid the risk of burns. 2) Xunda Yelong was a typical top-lit up draft (TLUD) biomass stove mainly designed for the wood. It had a much higher chamber than other four stoves and an additional plate to hold the wood. For this research using the charcoal, the bottom door was kept closed during burning. 3) EcoZoom Zoom Jet and 4) The EcoZoom Zoom Jet Economy were two very similar version charcoal stoves. With the same design, the Zoom Jet Economy was just a more portable and compact version of Zoom Jet; the differences of these two stoves were the top diameters, which were $28 \mathrm{~cm}$ and $26 \mathrm{~cm}$ respectively. The estimated lifespan by the manufacturer was $2-5$ years. As the ash removal door did not have a relatively accurate air control, and most of the time it would be fully opened to maintain the high power. 5) The Envirofit SuperSaver Premium, which was $32 \mathrm{~cm}$ diameter and $26 \mathrm{~cm}$ height, with the estimated lifespan by the manufacturer to be 4 to 7 years. The bottom ash removal door had a sliding window to control the power. It was much safer for all the improved stoves to have rubber feet or handles.

Table 2 Five stoves used in the test

1 Baseline stove

Note: All pictures come from the official website of the stove.

\subsection{Testing system}

Hood system was widely used for testing the small cooking stove without a chimney (Figure 1). A well-controlled three phases fan was used at the end of the hood system, making the velocity of the dilution tunnel to be $4.2 \mathrm{~m} / \mathrm{s}$, with the diameter of the dilution tunnel to be $15 \mathrm{~cm}$, the flow rate of the tunnel was $467.4 \mathrm{~m}^{3} / \mathrm{h}$. Hood face velocity was less than $0.2 \mathrm{~m} / \mathrm{s}$. The dilution tunnel was 3 meters length, and the flow measurement (TSI 5815) started at 1 meter after the elbow and followed by the gas analyzer (MRU VARIO PLUS). A thermocouple was put into the pot to measure the water temperature. One of the drawbacks using the hood system was it introduced air which was not from the combustion into the hood and required the measurement instruments to be much more accurate as the concentrations of gases could be diluted too much.

A water boiling method was designed combining the testing procedures requirements from current Chinese standard ${ }^{[30]}$ and the cooking habit in Africa. The Chinese testing procedure has a much easier way to tell the ending point as it requires the water temperature drop to $5^{\circ} \mathrm{C}$ below the boiling point, which regards the rest energy of the fuel cannot be used for a typical cooking. Moreover, a typical meal in Africa including a long time boiling or simmering such as cooking chicken feet. As a result, the research using stoves performed the same task, which brought ten pots of water to boil with lids on (normally around $4 \mathrm{~h}$ based on the performance of the stove). Pot would be replaced by the next normal temperature one after the water in the current pot reached

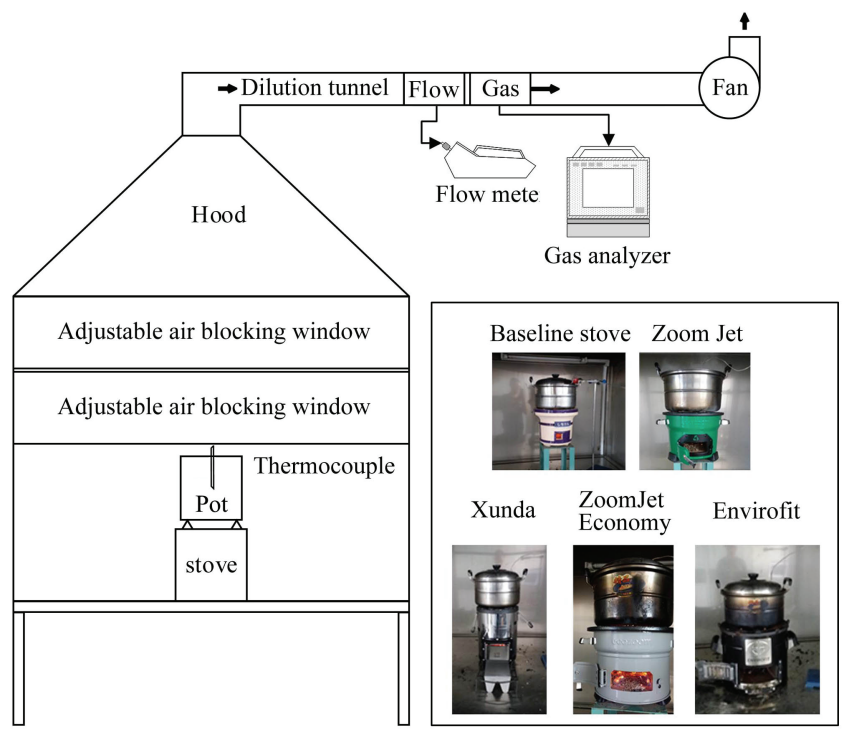

Figure 1 Hood testing system and stove testing pictures 
the boiling point. At the end of the tests, when the water in the tenth pot reaching the boiling point, the lid would be opened and evaporating water as required by the Chinese standard. The tests ended when the water temperature drop to $5^{\circ} \mathrm{C}$ below the boiling point.

\subsection{Outputs calculations}

Each test was repeated for three times. Emission factors used in this research was defined as the releasing emissions mass per useful energy, which was more helpful to the particular area stove promotion while the cooking task and cooking habit would not change after stove changes. Parameters calculated for the stove including thermal efficiency (\%), cooking power (W), CO EF $\left(\mathrm{g} / \mathrm{MJ}_{\text {net }}\right), \mathrm{CO} / \mathrm{CO}_{2}$ ratio (\%). All the statistical analysis of the difference in means was calculated using SPSS and probability of error of $p \leq 0.05$ was considered significant.

Thermal efficiency is an easier way to compare the fuel consumption of the stove with the normalized base. The similar parameter in some other testing methods or literature is specific fuel consumption ${ }^{[31]}$, which is the amount of moisture compensated charcoal required to produce certain energy directly reported in mass. Useful energy defined in this research including energy used by the water temperature rising and by the water evaporating, as well as energy absorbed by the pot. The releasing energy defined in this research including the energy released by the fuel and ignition material. All parts energy calculations were shown in the following equations (Equations (1)-(3)):

$$
\begin{aligned}
& \text { Released energy }(\mathrm{kJ})=\left[\left(\left(B_{f}-B_{c}\right) \times L_{1}\right)+\left(B_{0} \times L_{0}\right)\right] / 1000 \\
& \text { Useful energy }(\mathrm{kJ})=\left[\left[\left(T_{z 1}-T_{c 1}\right) \cdot S_{c 1}+\ldots+\left(T_{z n}-T_{c n}\right) \cdot S_{c n}\right] \cdot C_{w}+\right. \\
& \quad\left[\left(T_{z 1}-T_{c 1}\right) \cdot G_{1}+\ldots+\left(T_{z n}-T_{c n}\right) \cdot G_{n}\right] \cdot C_{p}+ \\
& \left.\quad\left(S_{c 10}-S_{f}\right) \cdot\left(r_{w}-5 C_{w}\right)\right] / 1000
\end{aligned}
$$

$$
\text { Thermal efficiency }(\%)=\frac{\text { Useful energy }}{\text { Released energy }} \times 100 \%
$$

where, $B_{c}$ is the initial fuel prepared for the test, $\mathrm{g} ; B_{f}$ is the final mass left unburned, g; $B_{0}$ is the mass of ignition material, g; $L_{1}$ and $L_{0}$ are respectively the air dry base lower heating value of the fuel and ignition material, $\mathrm{kJ} / \mathrm{kg} ; T_{z n}$ and $T_{c n}$ are respectively the final and initial water temperature of pot $n,{ }^{\circ} \mathrm{C} ; S_{c n}$ and $G_{n}$ are respectively the water mass and pot mass of pot $n, \mathrm{~g} ; C_{w}$ and $C_{p}$ are respectively the specific heat capacity of water and pot material, $\mathrm{kJ} /\left(\mathrm{kg} \cdot{ }^{\circ} \mathrm{C}\right) ; S_{f}$ is the finial water mass in pot 10 after evaporation; $r_{w}$ is the vaporization latent heat of water under normal condition.

The cooking power is used to report the cooking ability of the stove, while similar parameter in some other testing methods or literatures is called time to boil ${ }^{[31]}$. It is calculated using the Equation (4):

$$
\text { Cooking power }(\mathrm{W})=\frac{\text { Useful energy }}{t_{z}} \times 1000
$$

where, $t_{z}$ is the total testing duration, $\mathrm{s}$.

$\mathrm{CO}$ is an essential emission from the incomplete combustion of the stove. $\mathrm{CO} E F$ is calculated using the Equation (5):

$$
\mathrm{CO} \text { emission factor }\left(\frac{\mathrm{g}}{\mathrm{MJ}_{\mathrm{net}}}\right)=\frac{\int_{t_{c}}^{t_{j}} C O \cdot F_{y} d t \cdot \frac{28}{22.4} \times 1000}{\text { Useful energy }}
$$

where, $C O$ is introduced in unit ppm; $t_{c}$ is the initial time of $\mathrm{CO}$ measurement, $\mathrm{s} ; t_{j}$ is the finial time of $\mathrm{CO}$ measurement, $\mathrm{s} ; F_{y}$ is the flow rate of sampling duct in $\mathrm{L} / \mathrm{s}$.

$\mathrm{CO} / \mathrm{CO}_{2}$ ratio is the ratio of incomplete combustion and complete combustion, which is often being used to indicate the combustion situation. A smaller $\mathrm{CO} / \mathrm{CO}_{2}$ ratio means complete combustion. The similar parameter in some other testing methods or literature is modified combustion efficiency $(\mathrm{MCE})^{[31]}$, calculated as $\mathrm{CO}_{2} /\left(\mathrm{CO}+\mathrm{CO}_{2}\right)$.

\section{Results and discussion}

\subsection{Thermal efficiency}

The thermal efficiencies of five stoves were shown in Figure 2.

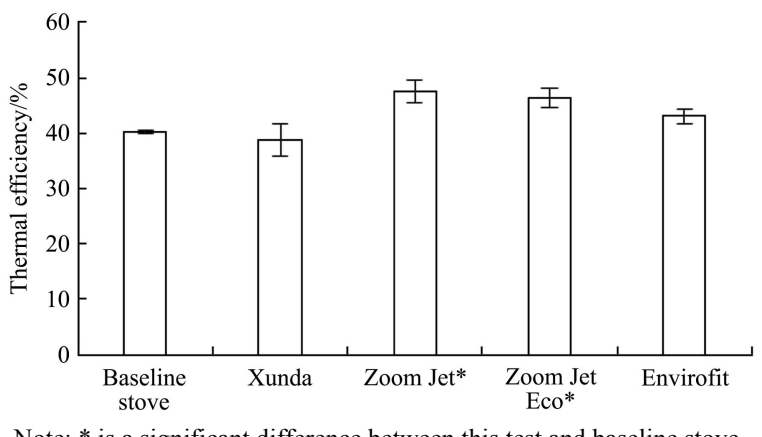

Note: $*$ is a significant difference between this test and baseline stove.

Figure 2 Thermal efficiency of five stoves

The thermal efficiencies for the Xunda and Environfit stoves were not significant different from that for the baseline, although Xunda $(38.7 \% \pm 2.9 \%)$ had a lower efficiency than the baseline $(40.2 \% \pm 0.2 \%)$, while Envirofit $(43.0 \% \pm 1.4 \%)$ was higher. The ventilation and heat transfer system of Xunda stove was not specifically designed for the charcoal stove which needed more air than burning the wood. If the front door of Xunda was kept half open during the test, it might have a better performance. Zoom Jet Economy and Zoom Jet all significantly improved than the baseline stove, and the differences between $28 \mathrm{~cm}$ or $26 \mathrm{~cm}$ stove size were not so important for the same design, and the users can choose according to the real needs.

The Equation (3) should be paid more attention, the energy used for water evaporation had a compensation of energy released when dropping to $5^{\circ} \mathrm{C}$ below the boiling point. Compensation was made because that part of energy had been calculated once during the temperature raising phase. The thermal performance of all the stove is relatively higher than the literatures reporting, which is usually within $17 \%$ to $40.7 \%^{[12,32-34]}$. Thermal efficiency and specific fuel consumption described the same aspect of the stove in different ways, with average numbers reporting a correlation with $R^{2}$ to be 0.96 (Figure 3 ). The only difference was that specific fuel consumption was a more intuitive way for end users in a particular region, where the cooking task and the fuel type had already been fixed; while thermal efficiency normalized the number by energy and can be used for more widely comparison. The good linear relationship indicted the two parameters could be chosen based on stockholders' needs to report thermal efficiency.

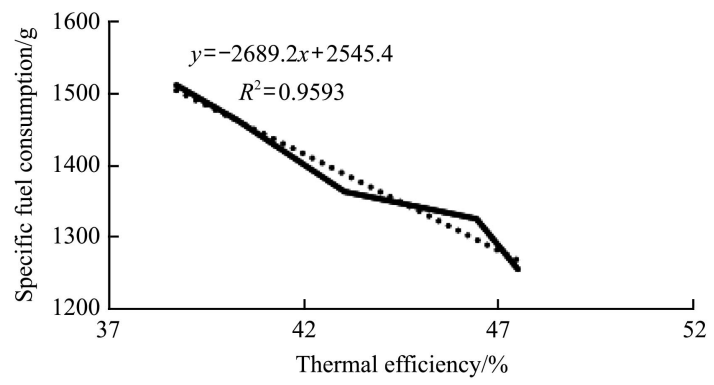

Figure 3 Correlation between thermal efficiency and specific fuel consumption 


\subsection{Cooking power}

The cooking powers of five stoves were shown in Figure 4. All four improved stoves had significant improvement than the baseline. The Environfit stove had the highest cooking power of 1202.1 $\pm 5.7 \mathrm{~W}$, that was double of the cooking power for the baseline charcoal stove $(642.5 \pm 92.6 \mathrm{~W})$, but still lower than most of the improved biomass stove using other fuel such as maize stalks or biomass pellet for $2-3 \mathrm{~kW}^{[33]}$. There was still no significant difference between Zoom Jet and Zoom Jet Economy, but the Zoom Jet Economy with smaller diameter had higher cooking power than Zoom Jet. Higher power may be because the fire in the small size stove was more concentrated and had a higher heating transfer efficiency.

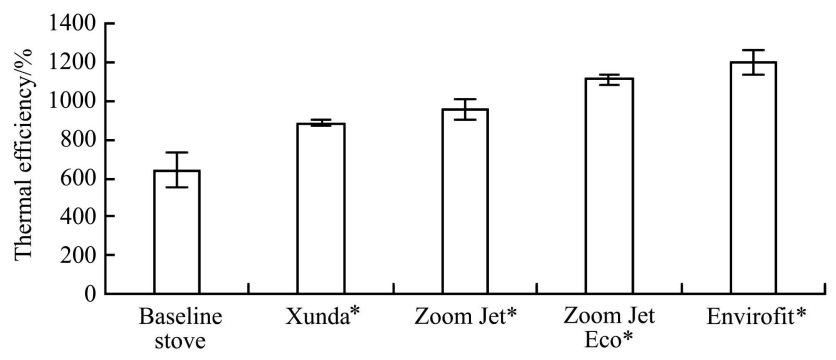

Note: * is a significant difference between this test and baseline stove.

Figure 4 Cooking powers of five stoves

Similar to the relationship of thermal efficiency and specific fuel consumption, time to boil was used as another way to describe the cooking ability. It was much easier for the end user of a particular region to know the stove performance and may not directly be used for comparison of the stove performance, as the water mass, fuel status and stove heat transfer efficiency all would have influences on this indicator. Figure 5 shows the correlation between average cooking power and time to boil. These two parameters could be chosen based on stockholders' needs to report the cooking power.

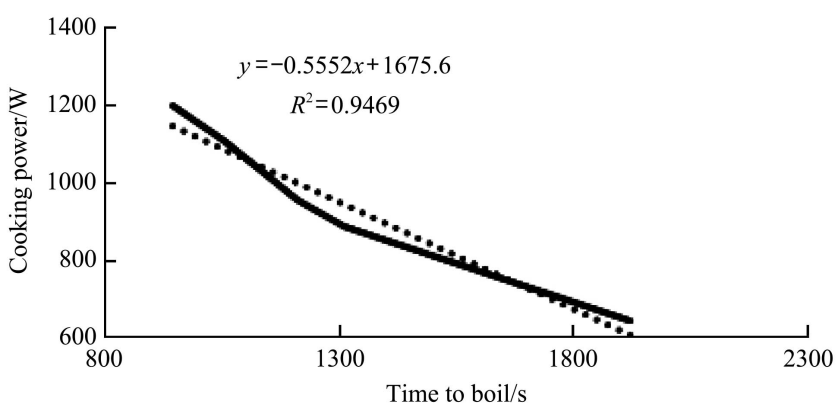

Figure 5 Correlation between cooking power and time to boil

One point should be noticed, as shown in Figure 6, the time to boil was longer for the first and last pot as the cooking power at ignition and burn phase of the fuel was relatively smaller. The cooking power in between was relatively stable. However, a different trend was monitored when the lid was removing. The evaporation phase was reporting a higher average cooking power with 1209.2 W compared with 1004.6 W during the pot changing phase, which was higher than the cooking power of last pot temperature raising phase. The lid-off evaporation method trend to report a higher cooking power. Reporting average cooking power was easy to compare the stove performance but at the same time may be losing the details of combustion. Real-time measurements and the influence of different combustion stages and operations on the cooking power still need to be studied.

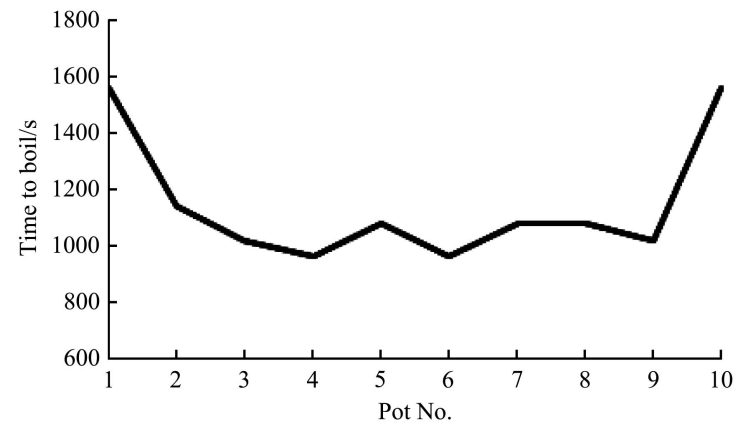

Figure 6 Typical times to boil of ten pots during one test

\subsection{CO emission factors}

The literatures might use fuel mass-based emission factor $\mathrm{g} / \mathrm{kg}^{[35]}$ or $\mathrm{g} / \mathrm{MJ}$ or even volume based concentration $\left(\mathrm{g} / \mathrm{m}^{3}\right)^{[33]}$ as the emission factor of the stove. In the purpose of stove performances comparison, the disadvantage of using fuel mass-based emission factors laid on the dependence of fuel types, which meant the result could not easily compared when testing using different fuels. Similarly, although the fuel energy based emission factor normalized the outputs by energy, it still did not consider the cooking tasks and cooking performances. The volume-based concentration is more related to the indoor air pollution but not the stove performance itself.

To overcome the disadvantage of the current emission factors, the useful energy-based "mass of CO per kilojoules of useful energy absorbed by the task $\left(\mathrm{g} / \mathrm{MJ}_{\text {net }}\right)$ " was used in this research. The useful energy based emission factor introduced heat transfer efficiency into account, which related to the cooking task and made the testing result more representative to the field use in certain area.

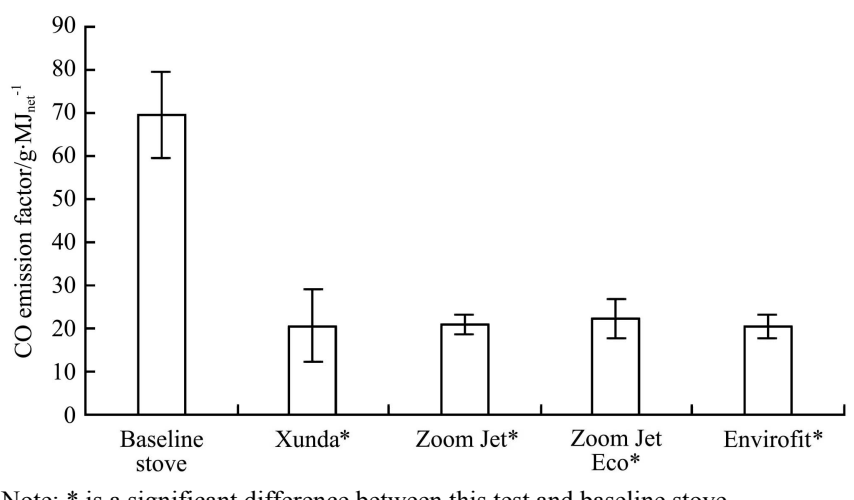

Figure 7 Useful energy based CO emission factor of five stoves

Although all other four stoves were significantly improved than the baseline stove $\left(69.7 \pm 10.1 \mathrm{~g} / \mathrm{MJ}_{\text {net }}\right)$, there is no significant difference among the four improved stoves with an average $21.1 \mathrm{~g} / \mathrm{MJ}_{\text {net }}$ (Figure 7). The result was different from MacCarty ${ }^{[32]}$, which says improved charcoal stove emits more CO than the baseline stove. Tryner ${ }^{[36]}$ uses the same base emission factors but with different fuels (corn cobs and wood pellets) reporting a $\mathrm{CO}$ emission factor between $3 \mathrm{~g} / \mathrm{MJ}_{\text {net }}$ to $80 \mathrm{~g} / \mathrm{MJ}_{\text {net }}$. Except for the fuel differences, the different results may also caused by using the different testing method as some of them using WBT v4.3.2 $2^{[31]}$. WBT requires the test to be finished as soon as the water temperature reaching the boiling point. That means no burnout phase was included in WBT. However, it was the starting and burn out phase that had the higher CO emission. Another interesting point was that whenever changing pot, the $\mathrm{CO}$ emission 
becomes bigger (Figure 8). This may because the cold pot touching with the hot flame and making the combustion temperature lower, at the same time the ventilation air flow also changed.

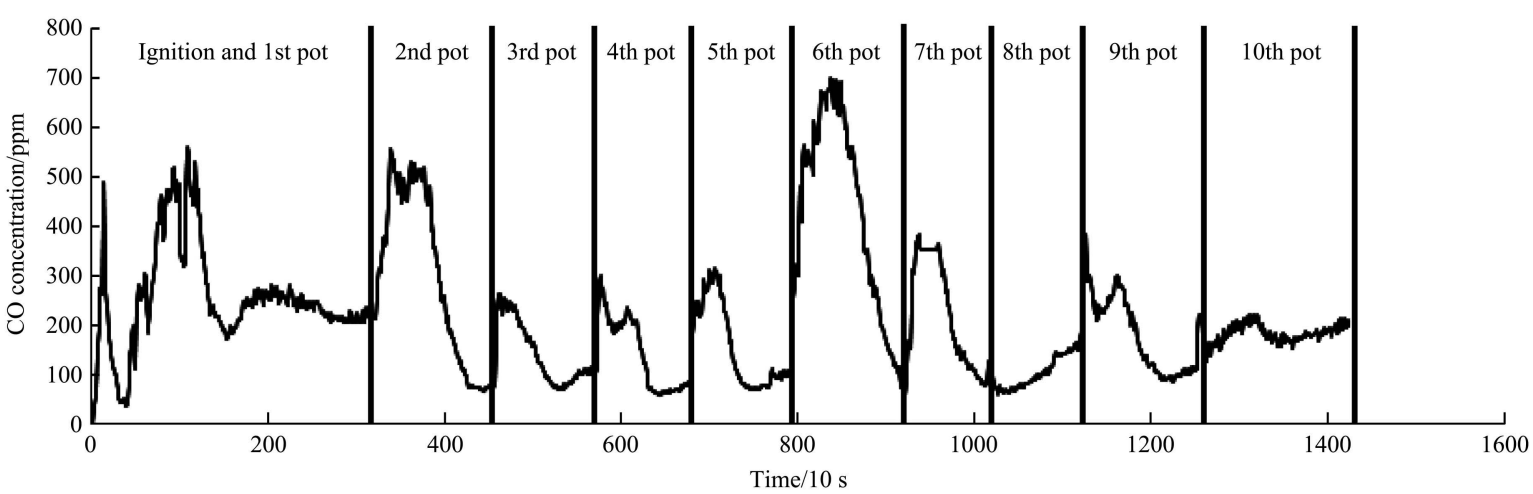

Figure 8 Typical $\mathrm{CO}$ emission of the ten-pot swapping test

\section{$3.4 \mathrm{CO} / \mathrm{CO}_{2}$ ratio}

As an indicator of the combustion status, the improved stove all had a better combustion than the baseline stove. There was no significant difference between the improved cooking stove. Not too much literatures reporting $\mathrm{CO} / \mathrm{CO}_{2}$ ratio, they reported $\mathrm{MCE}$ instead. Compared with literature reported MCE $89 \%$ to $92 \%$ using $\mathrm{WBT}^{[37]}$, this research reported a much higher number from $99.67 \%$ to $99.93 \%$. This result indicated that there was not too much room for improvement in combustion efficiency, the key issue laid on the heat transfer efficiency.

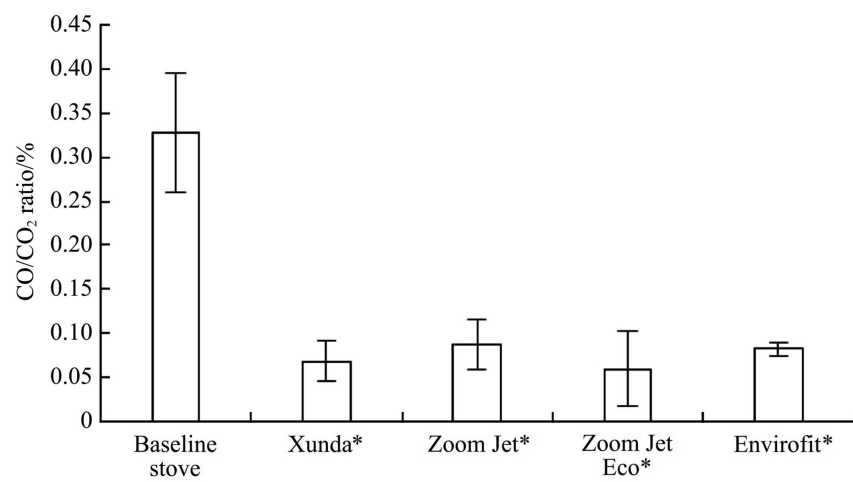

Note: * is a significant difference between this test and baseline stove.

Figure $9 \mathrm{CO} / \mathrm{CO}_{2}$ ratio of five stoves

\section{Conclusions}

Despite the thermal performance which has no significant differences, all the improved stoves have better performance on $\mathrm{CO}$ emission factor. Without considering the economic situation, only focusing on the single factor stove performance, for thermal efficiency or fuel consumption, Zoom Jet and Zoom Jet Eco are better than other stoves. However, Envirofit had the highest cooking power, which may cause by the bigger furnace or better air distribution. Although Xunda was not specifically designed for the charcoal, it still produced an acceptable result.

Three correlations between different indicators on the same aspect of the stove were analyzed in the research. As the results showed the good linear relationship between them, further study should choose the right indicators based on the project needs. If the project more focuses on the local stove improvement and the knowledge promotion, then the indicators such as time to boil and specific fuel combustion can be used; otherwise, if the test aiming at stove certification and comparison, more accurate indicators such as cooking power and thermal efficiency should be used.
Based on the testing results, the evaporation method tends to report a bigger cooking power, which should be considered if compare different testing methods. The $\mathrm{CO}$ has a big jump when changing pot, and more research should be carried out on the influences of pot on the combustion and emission.

\section{Acknowledgements}

The research was supported in part by Agricultural Product Quality Inspection Bureau Project - Agricultural Industry Standard Development for "Determination method of major atomosphere pollutants from rural household stoves" (No. 181721301092371112); the bilateral China-South Africa MoST-NRF joint project "Development of Scientifically Robust and Culturally Appropriate Metrics and Protocols for Evaluating Clean (Combustion) Cookstoves"; the World Bank Group Project for "Clean and Efficient Heating Stove South-South Knowledge Exchange" (No. 7182688); the Project for "China-Ghana Renewable Energy Technology Transfer Cooperation" (No. CG211/2-3) from the Administrative Center for China's Agenda 21.

\section{[References]}

[1] Bouzarovski S. Geographies of energy poverty and vulnerability in the European Union. Energie und soziale Ungleichheit: Springer, 2017; pp.29-53.

[2] Jewitt S, Raman S. Energy poverty, institutional reform and challenges of sustainable development: The case of India. Progress in Development Studies, 2017; 17(2): 173-185.

[3] Hou B D, Tang X, Ma C, Liu L, Wei Y M, Liao H. Cooking fuel choice in rural China: Results from microdata. Journal of Cleaner Production, 2017; 142: 538-547.

[4] Casillas C E, Kammen D M. The energy-poverty-climate nexus. Science, 2010; 330(6008): 1181-1182.

[5] Brew-Hammond A. Energy access in Africa: Challenges ahead. Energy Policy, 2010; 38(5): 2291-2301

[6] Government of India. Energy used by Indian households, 1999-2000, NSS 55th round, National Sample Survey Organisation, 2001.

[7] World Bank. China: Accelerating household access to clean cooking and heating. 2013. Available at: http://documents.worldbank.org/curated/ en/401361468022441202/China-Accelerating-household-access-to-clean-c ooking-and-heating. Accessed on [2017-09-18]

[8] Alakali J S, Kachataiya G T, Kucha C T. Evaluation of powered charcoal stove by using different biomass fuels. Int J of Agric \& Biol Eng, 2011; 4(2): 64-73.

[9] Treiber M U, Grimsby L K, Aune J B. Reducing energy poverty through increasing choice of fuels and stoves in Kenya: Complementing the multiple fuel model. Energy for Sustainable Development, 2015; 27: 54-62.

[10] Bansal M, Saini R, Khatod D. Development of cooking sector in rural areas in India-A review. Renewable and Sustainable Energy Reviews, 
2013; 17: 44-53.

[11] Edwards R D, Smith K R, Zhang J, Ma Y. Implications of changes in household stoves and fuel use in China. Energy Policy, 2004; 32(3): 395-411.

[12] Jetter J, Zhao Y, Smith K R, Khan B, Yelverton T, DeCarlo P, et al. Pollutant emissions and energy efficiency under controlled conditions for household biomass cookstoves and implications for metrics useful in setting international test standards. Environmental Science \& Technology, 2012; 46(19): 10827-10834.

[13] Khaing P, Mazumder S, Dube B, Taneja S, Yan B, Chillrud S, et al. Cardiovascular health effects of dung biomass smoke exposure: Effect modification by age. C60 Indoor air pollutants: Biomass and wood smoke, American Thoracic Society 2017 International Conference, American Journal of Respiratory and Critical Care Medicine, 2017; 195: A5983.

[14] Gorjinezhad S, Kerimray A, Torkmahalleh M A, Keleş M, Ozturk F, Hopke P K. Quantifying trace elements in the emitted particulate matter during cooking and health risk assessment. Environmental Science and Pollution Research, 2017; 24(10): 9515-9529.

[15] Liao H, Tang X, Wei Y M. Solid fuel use in rural China and its health effects. Renewable and Sustainable Energy Reviews, 2016; 60: 900-908.

[16] Röllin H. Evidence for health effects of early life exposure to indoor air pollutants: What we know and what can be done. Clean Air Journal, 2017; 27(1): 2-3.

[17] Smith K R, Shuhua G, Kun H, Daxiong Q. One hundred million improved cookstoves in China: How was it done? World Development, 1993; 21(6): 941-961.

[18] Venkataraman C, Sagar A, Habib G, Lam N, Smith K. The Indian national initiative for advanced biomass cookstoves: The benefits of clean combustion. Energy for Sustainable Development, 2010; 14(2): 63-72.

[19] Khandelwal M, Hill M E, Greenough P, Anthony J, Quill M, Linderman M, et al. Why Have Improved Cook-Stove Initiatives in India Failed? World Development, 2017; 92: 13-27.

[20] Sinton J E, Smith K R, Peabody J W, Liu Y P, Zhang X L, Edwards R, et al. An assessment of programs to promote improved household stoves in China. Energy for Sustainable Development, 2004; 8(3): 33-52.

[21] Yip F, Christensen B, Sircar K, Naeher L, Bruce N, Pennise D, et al. Assessment of traditional and improved stove use on household air pollution and personal exposures in rural western Kenya. Environment international, 2017; 99: 185-191.

[22] Medina P, Berrueta V, Martínez M, Ruiz V, Edwards R, Masera O. Comparative performance of five Mexican plancha-type cookstoves using water boiling tests. Development Engineering, 2017; 2: 20-28.

[23] Lask K, Booker K, Gadgil A. Lessons learned from a comparison study of charcoal stoves for Haiti. Sustainable Energy Technologies and Assessments, 2017.

[24] Obeng G Y, Mensah E, Ashiagbor G, Boahen O, Sweeney D J. Watching the smoke rise up: Thermal efficiency, pollutant emissions and global warming impact of three biomass cookstoves in Ghana. Energies, 2017;
10(5): 641-653.

[25] Shen G, Yang Y, Wang W, Tao S, Zhu C, Min Y, et al. Emission factors of particulate matter and elemental carbon for crop residues and coals burned in typical household stoves in China. Environmental Science \& Technology, 2010; 44(18): 7157-7162.

[26] Zhang J, Smith K, Ma Y, Ye S, Jiang F, Qi W, et al. Greenhouse gases and other airborne pollutants from household stoves in China: A database for emission factors. Atmospheric Environment, 2000; 34(26): 4537-4549.

[27] Carter E M, Shan M, Yang X, Li J, Baumgartner J. Pollutant emissions and energy efficiency of Chinese gasifier cooking stoves and implications for future intervention studies. Environmental Science \& Technology, 2014; 48(11): 6461-6467.

[28] Chen Y, Shen G, Su S, Du W, Huangfu Y, Liu G, et al. Efficiencies and pollutant emissions from forced-draft biomass-pellet semi-gasifier stoves: Comparison of international and Chinese water boiling test protocols. Energy for Sustainable Development, 2016; 32: 22-30.

[29] Zhang Z, Zhang Y, Zhou Y, Ahmad R, Pemberton-Pigott C, Annegarn H, et al. Systematic and conceptual errors in standards and protocols for thermal performance of biomass stoves. Renewable and Sustainable Energy Reviews, 2017; 72: 1343-1354.

[30] Ministry of Agriculture of the People's Republic of China. General technical specification of domestic biofuel cooking stove. NY/T 2370-2013. Beijing, 2013. (in Chinese)

[31] The water boiling test version 4.2 .3 cook stove emissions and efficiency in a controlled laboratory setting. Available at http://cleancookstoves.org/technology-and-fuels/testing/protocols.html. Accessed on [2014-02-08]

[32] MacCarty N, Still D, Ogle D. Fuel use and emissions performance of fifty cooking stoves in the laboratory and related benchmarks of performance. Energy for Sustainable Development, 2010; 14(3): 161-171.

[33] Grimsby L K, Rajabu H M, Treiber M U. Multiple biomass fuels and improved cook stoves from Tanzania assessed with the water boiling test. Sustainable Energy Technologies and Assessments, 2016; 14: 63-73.

[34] Adeyemi K, Lawal N, Asere A. Thermal performance of improved charcoal stove as a clean development mechanism project-A case study of Bauchi. FUOYE Journal of Engineering and Technology, 2017; 2(1): 21-26.

[35] Bhattacharya S, Salam P A. Low greenhouse gas biomass options for cooking in the developing countries. Biomass and Bioenergy, 2002; 22(4): 305-317.

[36] Tryner J, Willson B D, Marchese A J. The effects of fuel type and stove design on emissions and efficiency of natural-draft semi-gasifier biomass cookstoves. Energy for Sustainable Development, 2014; 23: 99-109.

[37] Lask K, Booker K, Han T, Granderson J, Yang N, Ceballos C, et al. Performance comparison of charcoal cookstoves for Haiti: Laboratory testing with water boiling and controlled cooking tests. Energy for Sustainable Development, 2015; 26: 79-86. 